\title{
Parity influences the severity of ACPA- negative early rheumatoid arthritis: a cohort study based on the Swedish EIRA material
}

Mitra Pikwer ${ }^{1,2,3,4^{*}}$, Cecilia Orellana ${ }^{2}$, Henrik Källberg ${ }^{2}$, Andreas Pikwer ${ }^{3}$, Carl Turesson $^{4}$, Lars Klareskog ${ }^{5}$, Lars Alfredsson ${ }^{2,6}$, Saedis Saevarsdottir ${ }^{2,5}$ and Camilla Bengtsson ${ }^{2}$

\begin{abstract}
Background: In women with rheumatoid arthritis (RA) it has been observed that during pregnancy a majority of patients experience amelioration, but after delivery a relapse of the disease is common. However, there are few studies, with diverging results, addressing the effect of parity on the severity of RA over time. Our aim was to explore the impact of parity, with stratification for anti-citrullinated protein antibody (ACPA) status as well as for onset during reproductive age or not.

Methods: Female RA cases aged 18-70 years were recruited for the Epidemiological Investigation of Rheumatoid Arthritis (EIRA). Information on disease severity (the health assessment questionnaire (HAQ) and the disease activity score 28 (DAS28)) was retrieved from the Swedish Rheumatology Quality Register at inclusion and 3, 6, 12 and 24 months after diagnosis. Mixed models were used to compare mean DAS28 and HAQ scores over time in parous and nulliparous women. Mean differences at individual follow-up visits were compared using analysis of covariance. The odds of having DAS28 or HAQ above the median in parous verus nulliparous women were estimated in logistic regression models.

Results: A total of 1237 female cases (mean age 51 years, 65 \% ACPA-positive) were included. ACPA-negative parous women, aged $18-44$ years, had on average 1.17 units higher DAS28 $(p<0.001)$ and 0.43 units higher HAQ score $(p<0.001)$ compared to nulliparous women during the follow-up time, adjusted for age. In this subgroup, the average DAS28 and HAQ scores were significantly higher in parous women at all follow-up time points. Younger parous ACPA-negative women were significantly more likely to have DAS28 and HAQ values above the median compared to nulliparous women at all follow-up visits. No association between parity and severity of ACPA-positive disease was observed.
\end{abstract}

Conclusions: Parity was a predictor of a more severe RA among ACPA-negative younger women, which might indicate that immunomodulatory changes during and after pregnancy affect RA severity, in particular for the ACPA-negative RA phenotype.

Keywords: Rheumatoid arthritis, Parity, Clinical outcome, Epidemiology, Hormonal factors

\footnotetext{
* Correspondence: mitra.pikwer@med.lu.se

'Rheumatology Unit, Mälarsjukhuset Hospital, Eskilstuna, Sweden

${ }^{2}$ Institute of Environmental Medicine, Karolinska Institutet, Stockholm, Sweden

Full list of author information is available at the end of the article
} 


\section{Background}

Female sex and older age are known risk factors for rheumatoid arthritis (RA). The disease is, however, heterogeneous, and a common division occurs between the presence/absence of autoantibodies to citrullinated peptide antigens (ACPA) where ACPA-positive disease generally has a worse outcome. Established genetic (e.g., HLA-DRB1 SE alleles) and environmental (e.g., smoking) risk factors are also predominantly associated with the risk of ACPApositive RA [1, 2].

Previous findings on the impact of parity on RA development have shown a reduction in RA incidence during pregnancy [3] and an increased risk post-partum [4]. In contrast, parity in the long run seems to have no association [5-7], or even reduced risk of RA [8]. In a recent study we reported that parous women of reproductive age had an increased risk of ACPA-negative RA, and that this increased risk was seen mainly in women who gave birth during the year of symptom onset. There was no association with risk of ACPA-positive RA [9].

In women with RA, it has been observed that during pregnancy a majority of patients experience amelioration $[10,11]$. After delivery a relapse of RA is common, especially in women who breastfeed $[12,13]$. There are only a few studies with diverging results regarding the effect of parity on the severity of RA (or inflammatory polyarthritis) over time [12-15]. Here, in an unselected populationbased cohort of early RA with extensive information about lifestyle and environmental factors, in a country with even access to healthcare, our aim was to explore the impact of parity on the severity of RA, with stratification for ACPA status as well as between those in reproductive age and those who were older at disease onset.

\section{Methods}

\section{The EIRA study}

We studied female incident RA cases aged 18-70 years, included between 1996 and 2009 in the Swedish Epidemiological Investigation of Rheumatoid Arthritis (EIRA) study, a population-based case-control study performed in parts of Sweden. EIRA has been described more extensively elsewhere [16]. All patients included were diagnosed by a rheumatologist and fulfilled the American College of Rheumatology 1987 criteria for RA [17]. The mean duration from symptom onset was 7 months. All participants gave informed consent and the study was approved by the Ethical Review Board at the Karolinska Institute.

\section{Data collection}

An extensive questionnaire was used to collect information on lifestyle and environmental factors, including parity. Of 2162 identified cases, 2063 (95\%) answered the questionnaire. In addition, the participating cases provided blood samples for serological and genetic analyses.
Women were classified as parous (those who had given birth before or during the year of diagnosis), or nulliparous at diagnosis. Information about parity history after diagnosis was not available. In total, 44 cases lacked information on parity.

\section{Antibody assays}

Immunoscan-RA Mark2 ELISA test (Euro-Diagnostica, Malmo, Sweden) was used to determine ACPA status [18]. The cut-off was set to $25 \mathrm{U} / \mathrm{ml}$ for ACPA-positive RA. Information about ACPA status was missing in 26 cases.

\section{Clinical outcome}

Clinical data were captured from the Swedish Rheumatology Quality Register (SRQ) until 2010. The register includes information about disease activity and disability at predefined time points. The process of capturing data on EIRA patients from SRQ was described previously [19]. There were 746 patients in EIRA who were not included in SRQ at inclusion in EIRA (baseline) or had missing disease activity parameters at baseline. Some of the patients had not yet reached the follow-up time points for data collection in SRQ (see below).

We focused on two outcome measures: the disease activity score 28 (DAS28) and the health assessment questionnaire (HAQ). These were evaluated at diagnosis and at the 3-, 6-, 12- and 24-month follow-up visits in SRQ. Not all repeated data were complete for DAS28 versus HAQ ( 0 versus $3 \%$ missing at inclusion, 19 versus $22 \%$ missing at 3 months, 34 versus $36 \%$ missing at 6 months, 10 versus $12 \%$ missing at 12 months and 27 versus $29 \%$ missing at 24 months).

\section{Statistics}

We stratified the cases into ACPA-negative/ACPA-positive disease, and age groups (18-44 and 45-70 years) [9]. We analyzed the data in three ways: 1) To compare mean DAS28 and HAQ scores over time in parous and nulliparous women we used mixed models with a first-order heterogeneous autoregressive correlation structure to allow for time-dependent variance and declining correlation between time points further away from each other. 2) Analysis of covariance was used to analyze differences in mean DAS28 and HAQ scores at the different time points between parous and nulliparous women, adjusted for age at inclusion in EIRA. We further adjusted individually for potential confounders (ever/never smoking; university/no university degree; ever/never use of oral contraceptives; and area of living). Questions about breastfeeding were added to the questionnaire in 2006 and a subanalysis on patients included in years 2006-2009 was performed with additional adjustment for ever/never breastfeeding amongst parous women. Adjustments for the abovementioned factors only marginally altered the 
results and were therefore not retained in the analyses. 3) Logistic regression was performed to obtain odds ratios with $95 \%$ confidence interval (CI) of having DAS28 or HAQ above the median at the different time points for parous women compared to nulliparous women.

All analysis was performed using Statistical Package for the Social Sciences22 IBM Corporation 1 New Orchard Road Armonk, New York 10504-1722 United States http://www-01.ibm.com/software/analytics/spss/ products/statistics/.

\section{Results}

In total, 1237 female cases with concurrent information on parity and ACPA status in EIRA were also included in the SRQ. Mean age at inclusion in EIRA was 52 years. The mean time between first symptoms and RA diagnosis was approximately 6 months, and no differences were found according to ACPA status. In all, $82 \%$ had ever given birth to a child before diagnosis and $65 \%$ were ACPA positive (Table 1).

\section{Disease severity over time: mixed models analysis}

Over time, parous women aged 18-44 years had on average higher DAS28 (mean difference 1.17, $95 \% \mathrm{CI}$ 0.65 to 1.68 ) and higher HAQ (mean difference 0.43, $95 \%$ CI 0.20 to 0.66 ) scores compared to nulliparous women at each follow-up (Table 2). Among women who developed ACPA-negative disease at older age, parous women tended to have a lower DAS28 (Table 2).

No association between parity and severity of ACPApositive disease was observed (Table 2).
Parity and severity of ACPA-negative RA at different time points: analysis of covariance

Since parity only had an impact on the outcome measures in the ACPA-negative subset, we limited further analyses to that group and compared mean differences at each follow-up visit (Table 3).

Parous women in the younger ACPA-negative group had significantly higher levels of HAQ and DAS28 in all repeated measurements except at baseline, where there were no differences. Among those aged $>45$ years at inclusion, parous women had lower levels of DAS28 and HAQ compared to nulliparous women at all time points, although the difference only reached statistical significance at baseline.

High verus low disease severity: logistic regression analysis Parous women who developed ACPA-negative disease at reproductive age had higher odds of having a DAS28 and $\mathrm{HAQ}$ value above the median compared to nulliparous women at all follow-up visits, with significance reached at 3, 12 and 24 months for DAS28 and at 12 months for HAQ. An indication of an opposite effect was seen in the ACPA-negative older group, especially at baseline (Table 4).

\section{Discussion}

In this study, we demonstrated that parity might have an impact on disease activity and disability in ACPA-negative disease. In those who developed RA at reproductive age (18-44 years), a more severe clinical outcome, measured with DAS28 and HAQ, was observed among parous as

Table 1 Baseline characteristics of incident rheumatoid arthrits cases included in EIRA

\begin{tabular}{|c|c|c|c|c|c|}
\hline & All women & ACPA negative & & ACPA positive & \\
\hline & & Aged $18-44(n=103)$ & Aged $45-70(n=331)$ & Aged $18-44(n=230)$ & Aged $45-70(n=573)$ \\
\hline Mean age, years (SD) & $51.5(12.8)$ & $32.9(7.0)$ & $58.8(6.6)$ & $34.3(7.4)$ & $57.6(7.0)$ \\
\hline Parous, n (\%) & 1009 (81.6) & $68(66.0)$ & $292(88.2)$ & $135(58.7)$ & $514(89.7)$ \\
\hline Nulliparous, n (\%) & $228(18.4)$ & $35(34.0)$ & $39(11.8)$ & $95(41.3)$ & $59(10.3)$ \\
\hline $\begin{array}{l}\text { Mean time between last birth to } \\
\text { symptom onset, years (SD) }\end{array}$ & $24.7(12.1)$ & $6.8(4.7)$ & $29.8(8.1)$ & $7.2(5.4)$ & $28.8(9.2)$ \\
\hline Mean age at first birth, years (SD) & $24(4.9)$ & $26(5.3)$ & $24(4.9)$ & $26(4.6)$ & $24(4.8)$ \\
\hline Mean number of children (SD) & $2.2(0.9)$ & $1.9(0.5)$ & $2.4(0.9)$ & $2.3(1.2)$ & $2.2(1.0)$ \\
\hline Median DAS28 at inclusion, years (SD) & $5.4(1.2)$ & $5.2(1.1)$ & $5.6(1.2)$ & $5.3(1.1)$ & $5.4(1.2)$ \\
\hline Median HAQ at inclusion (SD) & $1.0(0.6)$ & $1.0(0.5)$ & $1.1(0.6)$ & $1.0(0.6)$ & $1.1(0.6)$ \\
\hline Ever smokers, n (\%) & $823(66.7)$ & $59(57.3)$ & $202(61.2)$ & $126(55.0)$ & $436(76.2)$ \\
\hline University degree, n (\%) & $318(25.7)$ & $31(30.1)$ & $85(25.7)$ & $82(35.7)$ & $120(21.0)$ \\
\hline $\begin{array}{l}\text { Ever use of oral contraceptives before } \\
\text { symptom onset, } \mathrm{n}(\%)\end{array}$ & $807(65.6)$ & $89(89.0)$ & $195(59.1)$ & $185(81.1)$ & $338(59.1)$ \\
\hline Received DMARD at inclusion, n (\%) & $1109(87)$ & $91(87)$ & $304(90)$ & $190(87)$ & $522(89)$ \\
\hline Received prednisolone at inclusion, n (\%) & $476(37)$ & $32(29)$ & $133(38)$ & $70(31)$ & $241(40)$ \\
\hline
\end{tabular}

ACPA Anti-citrullinated protein antibody, DAS28 Disease activity score 28, DMARD Disease-modifying antirheumatic drug, EIRA Epidemiological Investigation of Rheumatoid Arthritis, HAQ Health assessment questionnaire, SD Standard deviation 
Table 2 Adjusted mean differences in clinical outcomes over the first 2 years between nulliparous and parous women

\begin{tabular}{|c|c|c|}
\hline & DAS28 & $\mathrm{HAQ}$ \\
\hline & Beta $(95 \%$ Cl), $p$-value & Beta $(95 \% \mathrm{Cl}), p$-value \\
\hline All patients & $\begin{array}{l}0.11(-0.05 \text { to } 0.27) \\
p=0.17\end{array}$ & $\begin{array}{l}0.06(-0.00 \text { to } 0.13) \\
p=0.07\end{array}$ \\
\hline \multicolumn{3}{|l|}{ ACPA negative } \\
\hline Aged 18-44 & $\begin{array}{l}1.17(0.65 \text { to } 1.68) \\
p<0.001\end{array}$ & $\begin{array}{l}0.43(0.20 \text { to } 0.66) \\
p<0.001\end{array}$ \\
\hline Aged 45-70 & $\begin{array}{l}-0.26(-0.62 \text { to } 0.09) \\
p=0.14\end{array}$ & $\begin{array}{l}-0.06(-0.20 \text { to } 0.09) \\
p=0.46\end{array}$ \\
\hline \multicolumn{3}{|l|}{ ACPA positive } \\
\hline Aged 18-44 & $\begin{array}{l}0.06(-0.25 \text { to } 0.38) \\
p=0.69\end{array}$ & $\begin{array}{l}0.07(-0.05 \text { to } 0.19) \\
p=0.27\end{array}$ \\
\hline Aged 45-70 & $\begin{array}{l}0.08(-0.20 \text { to } 0.36) \\
p=0.57\end{array}$ & $\begin{array}{l}0.02(-0.10 \text { to } 0.14) \\
p=0.70\end{array}$ \\
\hline
\end{tabular}

Mixed models adjusted for age at inclusion in the Epidemiological Investigation of Rheumatoid Arthritis (EIRA), with nulliparous women as reference. ACPA Anti-citrullinated protein antibody, $C$ c confidence interval, $D A S 28$ Disease activity score $28, H A Q$ Health assessment questionnaire

Table 3 Analysis of covariance with mean differences of outcome measures (DAS28, HAQ) between nulliparous and parous women with incident RA included in the EIRA study, at baseline and follow-up visits during the first 24 months

\begin{tabular}{|c|c|c|}
\hline \multirow{3}{*}{$\begin{array}{l}\text { Outcome measure } \\
\text { above median }\end{array}$} & \multicolumn{2}{|l|}{ ACPA-negative RA } \\
\hline & $18-44$ years & $45-70$ years \\
\hline & Beta $(95 \% \mathrm{Cl})$, $p$-value & Beta (95\% Cl), $p$-value \\
\hline \multicolumn{3}{|l|}{ DAS28 } \\
\hline Baseline & $\begin{array}{l}0.02(-0.58 \text { to } 0.62), \\
p=0.95\end{array}$ & $\begin{array}{l}-0.78(-1.19 \text { to }-0.37) \\
p<0.001\end{array}$ \\
\hline 3 months & $\begin{array}{l}1.60(0.81 \text { to } 2.40) \\
p<0.001\end{array}$ & $\begin{array}{l}-0.45(-0.96 \text { to } 0.06) \\
p=0.96\end{array}$ \\
\hline 6 months & $\begin{array}{l}1.30(0.48 \text { to } 2.12) \\
p=0.002\end{array}$ & $\begin{array}{l}-0.27(-0.82 \text { to } 0.28) \\
p=0.34\end{array}$ \\
\hline 12 months & $\begin{array}{l}1.22(0.59 \text { to } 1.85) \\
P<0.001\end{array}$ & $\begin{array}{l}-0.31(-0.73 \text { to } 0.12) \\
p=0.16\end{array}$ \\
\hline 24 months & $\begin{array}{l}0.86(0.18 \text { to } 1.55) \\
p=0.014\end{array}$ & $\begin{array}{l}-0.29(-0.76 \text { to } 0.19) \\
p=0.24\end{array}$ \\
\hline \multicolumn{3}{|l|}{$\mathrm{HAQ}$} \\
\hline Baseline & $\begin{array}{l}0.06(-0.23 \text { to } 0.34) \\
p=0.68\end{array}$ & $\begin{array}{l}-0.35(-0.56 \text { to }-0.14), \\
p=0.001\end{array}$ \\
\hline 3 months & $\begin{array}{l}0.40(0.05 \text { to } 0.74) \\
p=0.026\end{array}$ & $\begin{array}{l}-0.12(-0.32 \text { to } 0.08) \\
p=0.24\end{array}$ \\
\hline 6 months & $\begin{array}{l}0.44(0.13 \text { to } 0.75) \\
p=0.006\end{array}$ & $\begin{array}{l}-0.09(-0.30 \text { to } 0.12) \\
p=0.38\end{array}$ \\
\hline 12 months & $\begin{array}{l}0.43 \text { (0.16 to } 0.69) \\
p=0.002\end{array}$ & $\begin{array}{l}-0.02(-0.20 \text { to } 0.16) \\
p=0.80\end{array}$ \\
\hline 24 months & $\begin{array}{l}0.48 \text { (0.14 to } 0.82) \\
p=0.006\end{array}$ & $\begin{array}{l}-0.17(-0.38 \text { to } 0.05) \\
p=0.13\end{array}$ \\
\hline
\end{tabular}

Analysis of covariance adjusted for age at inclusion in the Epidemiological Investigation of Rheumatoid Arthritis (EIRA), with nulliparous women as reference. ACPA Anti-citrullinated protein antibody, $\mathrm{Cl}$ confidence interval, $D A S 28$ Disease activity score $28, H A Q$ health assessment questionnaire, $R A$ Rheumatoid arthritis
Table 4 Logistic regression for parous women compared to nulliparous women

\begin{tabular}{|c|c|c|}
\hline \multirow{3}{*}{$\begin{array}{l}\text { Outcome measure } \\
\text { above median }\end{array}$} & \multicolumn{2}{|l|}{ ACPA-negative RA } \\
\hline & Aged $18-44$ & Aged $45-70$ \\
\hline & OR (95\% Cl), p-value & OR (95\% Cl), p-value \\
\hline \multicolumn{3}{|l|}{ DAS28 } \\
\hline Baseline & $\begin{array}{l}1.87(0.62 \text { to } 5.69) \\
p=0.27\end{array}$ & $\begin{array}{l}0.37 \text { (0.18 to } 0.80) \\
p=0.011\end{array}$ \\
\hline 3 months & $\begin{array}{l}4.96(1.37 \text { to } 18.1) \\
p=0.015\end{array}$ & $\begin{array}{l}0.51(0.24 \text { to } 1.08), \\
p=0.08\end{array}$ \\
\hline 6 months & $\begin{array}{l}2.66 \text { (0.78 to } 9.15) \\
p=0.12\end{array}$ & $\begin{array}{l}0.37 \text { (0.16 to } 0.85), \\
p=0.018\end{array}$ \\
\hline 12 months & $\begin{array}{l}4.49(1.37 \text { to } 14.7) \\
p=0.013\end{array}$ & $\begin{array}{l}0.89 \text { (0.44 to } 1.77), \\
p=0.97\end{array}$ \\
\hline 24 months & $\begin{array}{l}3.56(1.07 \text { to } 11.9) \\
p=0.039\end{array}$ & $\begin{array}{l}0.67(0.30 \text { to } 1.50) \\
p=0.33\end{array}$ \\
\hline \multicolumn{3}{|l|}{ HAQ } \\
\hline Baseline & $\begin{array}{l}0.58(0.20 \text { to } 1.69) \\
p=0.32\end{array}$ & $\begin{array}{l}0.53(0.26 \text { to } 1.07) \\
p=0.08\end{array}$ \\
\hline 3 months & $\begin{array}{l}3.04(0.90 \text { to } 10.3) \\
p=0.07\end{array}$ & $\begin{array}{l}1.29(0.62 \text { to } 2.67), \\
p=0.50\end{array}$ \\
\hline 6 months & $\begin{array}{l}2.42(0.71 \text { to } 8.23) \\
p=0.16\end{array}$ & $\begin{array}{l}1.01(0.47 \text { to } 2.14), \\
p=0.99\end{array}$ \\
\hline 12 months & $\begin{array}{l}7.92(2.02 \text { to } 31.0) \\
p=0.003\end{array}$ & $\begin{array}{l}1.15(0.57 \text { to } 2.33), \\
p=0.69\end{array}$ \\
\hline 24 months & $\begin{array}{l}2.14 \text { (0.65 to } 7.06) \\
p=0.21\end{array}$ & $\begin{array}{l}0.95(0.42 \text { to } 2.17) \\
p=0.90\end{array}$ \\
\hline
\end{tabular}

Logistic regression adjusted for age at inclusion in the Epidemiological Investigation of Rheumatoid Arthritis (EIRA), with the odds ratio (OR) of having an outcome measure (DAS28 and $\mathrm{HAQ}$ ) higher than median for a parous woman. ACPA Anti-citrullinated protein antibody, $\mathrm{Cl}$ confidence interval, DAS28 Disease activity score $28, H A Q$ Health assessment questionnaire

compared to nulliparous women. In the older age group (45-70 years at inclusion) we observed a milder disease in parous women, though only statistically significant at baseline. There was no association between parity and the severity of ACPA-positive disease, neither among younger nor among older women.

In a recent study we showed that parous women of reproductive age (18-44) had a higher risk of ACPAnegative disease, and we now show that their disease course also seems to be more severe [10]. Regarding the effect of parity on RA severity over time, there are two previous studies with somewhat diverging results $[13,14]$. However, this is the first study investigating the association between parity and the severity of RA with stratification for ACPA status.

Strengths of this study include the frequent follow-up program and the large sample size, which allows us to perform stratified analyses of different RA subgroups, as well as different age groups. The inclusion of only incident cases also ascertains that parity was not affected by the disease. 
One limitation was the lack of information about parity after diagnosis. If ACPA-negative women had more pregnancies after disease onset it might have affected our results on disease severity over time. However, the number of women who might have become pregnant within the 2-year follow-up time is probably limited (178 women were in the age group 18-35 years). Another limitation was the lack of disease severity parameters at baseline in a subset of patients. In a failure analysis, no major differences in parity (78 versus $82 \%$ in the presented population) or university degree (26 versus $26 \%$ ) were found for those included in EIRA only compared to those included in both EIRA and SRQ.

Hypothetically, our findings may be explained by immunomodulatory changes related to pregnancy, for example a decrease of anti-inflammatory cytokines [20] and regulatory CD4+ T cells [21] postpartum, which could drive the progression of ACPA-negative RA in younger women, especially close to delivery. In a study of a population of North American natives highly predisposed to RA, the highest incidence of RA was observed in the first postpartum year [22]. This suggests that reversal of hormonal and immunologic changes during pregnancy that favor immune tolerance (and prevent maternal rejection of the fetus) may affect RA development and increase early disease severity.

The impact of parity on disease activity and disability in ACPA-negative disease among women aged 18-44 years might be confined to the postpartum period. However, since there were too few observations to study RA progression directly after delivery, we included all women aged 18-44 years in the analysis. Another hypothesis is that ACPA-negative younger women who had been pregnant could have poorer response to treatment or lesser compliance to prescribed medications than ACPA-negative women who had not yet been pregnant, certainly if they are planning new pregnancies. However, we cannot exclude that women who had not been pregnant before diagnosis also are planning pregnancy in the near future.

Other possible explanations include an impact of sleep disturbance and other factors that could influence pain in the postpartum period. This should be further studied.

In older women, the influence of parity may reflect the influence of related lifestyle factors, or a long-term impact of hormone-related factors, which have been shown to be more important for seronegative RA [23].

\section{Conclusion}

Parity may be a predictor of higher DAS28 and HAQ compared to nulliparity in ACPA-negative RA women of reproductive age at diagnosis, but seemed to be a predictor of less severe disease amongst older women, at least at baseline. Parity did not seem to be a predictor of severity in ACPA-positive disease. These findings indicate that immunomodulatory changes during and after pregnancy may have specific impact on the ACPA-negative RA phenotype. Further studies of the underlying mechanisms may be the basis for a particular management of ACPAnegative younger women with RA in the future.

\section{Abbreviations}

ACPA: Anti-citrullinated protein antibodies; Cl: confidence interval; DAS28: Disease activity score 28; EIRA: Epidemiological Investigation of Rheumatoid Arthritis; HAQ: Health assessment questionnaire; RA: Rheumatoid arthritis; SRQ: Swedish Rheumatology Quality Register.

\section{Competing interests}

The authors declare that they have no competing interests.

\section{Authors' contributions}

MP was responsible for initiating the study, analysis and writing the paper. $\mathrm{CO}$ and $\mathrm{CB}$ were responsible for initiating the study, analysis and revising the manuscript. SS and CT contributed with clinical perspective to the statistical analyses and the interpretation of the results. HK and AP contributed to the statistical analyses. LK and LA are principal investigators of the EIRA study, and contributed to the planning of the study and the interpretation of the results. All authors contributed to the writing of the final article. All authors read and approved the final manuscript.

\section{Acknowledgements}

We would like to thank all the patients who participated in the study, and all clinicians and nurses in the EIRA study group. We also thank Niklas Mattson for statistical guidance. MP was supported by a stipend from the Swedish Society for Rheumatology, funded by an unrestricted grant from Abbvie. This study was supported by grants from the Swedish Medical Research Council, the Swedish Research Council for Health, Working Life and Welfare, King Gustav V's 80-year foundation, the Swedish Rheumatic Foundation, the Stockholm County Council, Lund University, the Insurance Company AFA, the Innovative Medicines Initiative-supported BTCure project, the Controlling Chronic Inflammatory Diseases with Combined Efforts project and the National Institutes of Health (NIH, AR047782).

\section{Author details}

${ }^{1}$ Rheumatology Unit, Mälarsjukhuset Hospital, Eskilstuna, Sweden. ${ }^{2}$ Institute of Environmental Medicine, Karolinska Institutet, Stockholm, Sweden. ${ }^{3}$ Centre for Clinical Research Sörmland, Uppsala University, Eskilstuna, Sweden. ${ }^{4}$ Rheumatology, Department of Clinical Sciences, Malmö, Lund University, Malmö, Sweden. ${ }^{5}$ Rheumatology Unit, Department of Medicine, Karolinska Institutet and Karolinska University Hospital Solna, Stockholm, Sweden.

${ }^{6} \mathrm{Centre}$ of Occupational and Environmental Medicine, Stockholm County Council, Stockholm, Sweden.

Received: 21 May 2015 Accepted: 20 November 2015 Published online: 12 December 2015

\section{References}

1. Karlson EW, Deane K. Environmental and gene-environment interactions and risk of rheumatoid arthritis. Rheum Dis Clin North Am. 2012;38:405-26.

2. Kallberg H, Padyukov L, Plenge RM, Ronnelid J, Gregersen PK, van der Helm-van Mil AH, et al. Gene-gene and gene-environment interactions involving HLA-DRB1, PTPN22, and smoking in two subsets of rheumatoid arthritis. Am J Hum Genet. 2007:80:867-75.

3. Straub RH, Buttgereit F, Cutolo M. Benefit of pregnancy in inflammatory arthritis. Ann Rheum Dis. 2005;64:801-3.

4. Wallenius M, Skomsvoll JF, Irgens LM, Salvesen KA, Koldingsnes W, Mikkelsen K, et al. Postpartum onset of rheumatoid arthritis and other chronic arthritides: results from a patient register linked to a medical birth registry. Ann Rheum Dis. 2010;69:332-6.

5. Jorgensen KT, Pedersen BV, Jacobsen S, Biggar RJ, Frisch M. National cohort study of reproductive risk factors for rheumatoid arthritis in Denmark: a role for hyperemesis, gestational hypertension and pre-eclampsia? Ann Rheum Dis. 2010;69:358-63. 
6. Pikwer M, Bergstrom U, Nilsson JA, Jacobsson L, Berglund G, Turesson C. Breast feeding, but not use of oral contraceptives, is associated with a reduced risk of rheumatoid arthritis. Ann Rheum Dis. 2009;68:526-30.

7. Karlson EW, Mandl LA, Hankinson SE, Grodstein F. Do breast-feeding and other reproductive factors influence future risk of rheumatoid arthritis? Results from the Nurses' Health Study. Arthritis Rheum. 2004:50:3458-67.

8. Guthrie KA, Dugowson CE, Voigt LF, Koepsell TD, Nelson JL. Does pregnancy provide vaccine-like protection against rheumatoid arthritis? Arthritis Rheum. 2010;62:1842-8.

9. Orellana C, Wedren S, Kallberg H, Holmqvist M, Karlson EW, Alfredsson L, et al. Parity and the risk of developing rheumatoid arthritis: results from the Swedish Epidemiological Investigation of Rheumatoid Arthritis study. Ann Rheum Dis. 2013;73(4):752-5.

10. de Man YA, Hazes JM, van de Geijn FE, Krommenhoek C, Dolhain RJ. Measuring disease activity and functionality during pregnancy in patients with rheumatoid arthritis. Arthritis Rheum. 2007;57:716-22.

11. Nelson JL, Ostensen M. Pregnancy and rheumatoid arthritis. Rheum Dis Clin North Am. 1997;23:195-212.

12. Barrett $J H$, Brennan $P$, Fiddler M, Silman A. Breast-feeding and postpartum relapse in women with rheumatoid and inflammatory arthritis. Arthritis Rheum. 2000;43:1010-5.

13. Jorgensen C, Picot MC, Bologna C, Sany J. Oral contraception, parity, breast feeding, and severity of rheumatoid arthritis. Ann Rheum Dis. 1996;55:94-8.

14. Camacho EM, Harrison M, Farragher TM, Lunt M, Bunn DK, Verstappen SM, et al. Parity, time since last live birth and long-term functional outcome: a study of women participating in the Norfolk Arthritis Register. Ann Rheum Dis. 2011;70:642-5.

15. Drossaers-Bakker KW, Zwinderman AH, van Zeben D, Breedveld FC, Hazes JM. Pregnancy and oral contraceptive use do not significantly influence outcome in long term rheumatoid arthritis. Ann Rheum Dis. 2002;61:405-8.

16. Bengtsson C, Berglund A, Serra ML, Nise L, Nordmark B, Klareskog L, et al. Non-participation in EIRA: a population-based case-control study of rheumatoid arthritis. Scand J Rheumatol. 2010;39:344-6.

17. Arnett FC, Edworthy SM, Bloch DA, MCShane DJ, Fries JF, Cooper NS, et al. The American Rheumatism Association 1987 revised criteria for the classification of rheumatoid arthritis. Arthritis Rheum. 1988;31:315-24.

18. Ronnelid J, Wick MC, Lampa J, Lindblad S, Nordmark B, Klareskog L, et al. Longitudinal analysis of citrullinated protein/peptide antibodies (anti-CP) during 5 year follow up in early rheumatoid arthritis: anti-CP status predicts worse disease activity and greater radiological progression. Ann Rheum Dis. 2005;64:1744-9.

19. Saevarsdottir S, Wedren S, Seddighzadeh M, Bengtsson C, Wesley A, Lindblad S, et al. Patients with early rheumatoid arthritis who smoke are less likely to respond to treatment with methotrexate and tumor necrosis factor inhibitors: observations from the Epidemiological Investigation of Rheumatoid Arthritis and the Swedish Rheumatology Register cohorts. Arthritis Rheum. 2011;63:26-36

20. Ostensen M, Forger F, Nelson JL, Schuhmacher A, Hebisch G, Villiger PM Pregnancy in patients with rheumatic disease: anti-inflammatory cytokines increase in pregnancy and decrease post partum. Ann Rheum Dis. 2005;64:839-44.

21. Amin S, Peterson EJ, Reed AM, Mueller DL. Pregnancy and rheumatoid arthritis: insights into the immunology of fetal tolerance and control of autoimmunity. Curr Rheumatol Rep. 2011;13:449-55.

22. Peschken CA, Robinson DB, Hitchon CA, Smolik I, Hart D, Bernstein CN, et al Pregnancy and the risk of rheumatoid arthritis in a highly predisposed North American Native population. J Rheumatol. 2012;39:2253-60.

23. Pikwer M, Bergstrom U, Nilsson JA, Jacobsson L, Turesson C. Early menopause is an independent predictor of rheumatoid arthritis. Ann Rheum Dis. 2012;71:378-81

\section{Submit your next manuscript to BioMed Central and we will help you at every step:}

- We accept pre-submission inquiries

- Our selector tool helps you to find the most relevant journal

- We provide round the clock customer support

- Convenient online submission

- Thorough peer review

- Inclusion in PubMed and all major indexing services

- Maximum visibility for your research

Submit your manuscript at www.biomedcentral.com/submit 